http://dx.doi.org/10.35381/racji.v5i1.630

\title{
Perspectiva de género en actuaciones y resoluciones judiciales contra la violencia a la mujer
}

\section{Gender perspective in legal proceedings and resolutions against violence against women}

Rossi Fabiola Peñafiel-Bermeo

rossi.penafiel@psg.ucacue.edu.ec

Universidad Católica de Cuenca, Cuenca

Ecuador

https://orcid.org/0000-0003-4696-9442

Cecilia Ivonne Narváez-Zurita

inarvaez@ucacue.edu.ec

Universidad Católica de Cuenca, Cuenca

Ecuador

https://orcid.org/0000-0002-7437-9880

José Luis Vázquez-Calle

jlvazquezc@ucacue.edu.ec

Universidad Católica de Cuenca, Cuenca

Ecuador

https://orcid.org/0000-0003-4980-6403

Juan Carlos Erazo-Álvarez

jcerazo@ucacue.edu.ec

Universidad Católica de Cuenca, Cuenca

Ecuador

https://orcid.org/0000-0001-6480-2270

Recibido: 15 de noviembre de 2019

Aprobado: 16 de diciembre de 2019

\section{RESUMEN}

Los Jueces/as deben aplicar la perspectiva de género, en aquellos casos que devienen hechos de violencia contra las mujeres, por cuanto ejercitan un rol transformador ante la desigualdad formal, material y estructural al momento de conocer los procesos, al juzgar son agentes de cambio en el diseño y ejecución del proyecto de vida de las personas, el fin del derecho es combatir las relaciones asimétricas de poder, esquemas 
de desigualdad que afectan el desarrollo de hombres y mujeres dentro de la sociedad. Estas decisiones judiciales no solo deben garantizar derechos, sino también deben ser preventivas, y necesarias para erradicar una vida libre de violencia contra las mujeres. El tipo de investigación aplicada en el artículo fue cualitativa-cuantitativa, con énfasis en una investigación cualitativa que dentro de la Argumentación Jurídica por parte de Jueces/as incorpora los enfoques de igualdad desde la perspectiva de género en la violencia contra las mujeres.

Descriptores: Enfoques de igualdad; perspectiva de género; prejuicios y estereotipos; violencia contra las mujeres; desigualdad social.

\section{ABSTRACT}

Judges must apply the gender perspective, in those cases that become acts of violence against women, because they exercise a transformative role in the face of formal, material and structural inequality when knowing the processes, when judging they are agents of change In the design and execution of people's life projects, the purpose of law is to combat asymmetric power relations, inequality schemes that affect the development of men and women within society. These judicial decisions must not only guarantee rights, but also must be preventive, and necessary to eradicate a life free of violence against women. The type of research applied in the article was qualitativequantitative, with emphasis on qualitative research that, within the Legal Argument by Judges, incorporates the approaches of equality from a gender perspective in violence against women.

Descriptors: Equality approaches; gender perspective; prejudices and stereotypes; violence against women; social inequality.

\section{INTRODUCCIÓN}

La perspectiva de género dentro de la Administración de Justicia conforme lo determina la Cumbre Iberoamericana de Derechos Humanos debe ser aplicada por parte de los operadores de justicia, para ello es necesario tomar en cuenta que los mitos sobre la violencia contra la mujer y la violencia basada en género se producen en cada sociedad de acuerdo a su historia, cultura, y también conforme al tiempo o época, que han sido aprendidos en distintos espacios de la sociedad y se han evidenciado por diversos 
comportamientos naturales del ser humano, sean hombres o mujeres (Cumbre Judicial Iberoamericana Comisión Permanente de Género y Acceso a la Justicia, 2015).

Lo estereotipos de género se usan con frecuencia para justificar de manera general la discriminación en la que se reflejan por formas tradicionales y conservadoras, así como sus prácticas institucionales que se encuentran en la vida cotidiana. Por ejemplo, el lenguaje en el que se puede evidenciar estereotipos y prejuicios no solo en el ámbito familiar, social, también laboral y político tales como: linda como madre, sólo los hombres pueden son fuertes porque las mujeres son sutiles, los hombres pueden ejercitar todas las profesiones, las mujeres sólo pueden desempeñarse como amas de casa (ONU Mujeres, 2016).

Las normas sociales procuran que dentro de la masa poblacional se interiorice que determinadas prácticas sociales se las produzca como verdades, se naturalicen, se normalicen como costumbres y estas se vuelvan a reproducir formando parte de las relaciones sociales en el diario vivir. La perspectiva de género debe ser transversal en el servicio de la Administración de Justicia, de tal modo que coadyuve a modificar las relaciones y pautas de comportamiento humano, desmontando y destruyendo así todas las prácticas discriminatorias en la sociedad (Ministerio de Justicia y Derechos Humanos, 2009).

El derecho debe contribuir a superar el conjunto de características estereotipadas y prejuicios que la sociedad asigna a mujeres y varones, y la incorporación de estos cambios en el ámbito de aplicación de normas tiene sus propios tiempos, de ahí que a pesar del reconocimiento legal de los derechos humanos y en especial énfasis los derechos de las mujeres, todavía se observan decisiones judiciales que parecieran no advertir la existencia de los estereotipos y prejuicios arraigados de comportamientos basados en conceptos de inferioridad o subordinación hacia la mujer (Piqué y Pzellinsky, 2015).

El concepto de género es un constructo social que deviene de generación en generación por décadas, desde nuestros antepasados, se mantiene y se reproduce, 
principalmente en el ámbito simbólico del lenguaje y de la cultura. Mientras estos cambios culturales se producen cotidianamente dentro de la sociedad, es al órgano judicial que le compete impulsar estas modificaciones, de-construyendo prejuicios y estereotipos a través de sus resoluciones o sentencias que renuevan dicho comportamiento reproduciendo nuevos roles desde una perspectiva de género para el quehacer tanto de varones y mujeres en las mismas condiciones con enfoque de igualdad, transversalizado hacia los derechos humanos y aplicarlos de forma directa en la resolución de conflictos sometidos a los operadores de justicia (Consejo Nacional para la Igualdad de Género, 2017).

Bajo el contexto antes expuesto, el presente trabajo plantea como problema de la investigación la necesidad de que los operadores de justicia incorporen en sus argumentos jurídicos los enfoques de igualdad y apliquen desde una perspectiva de género, tomando en cuenta que ejercen un papel fundamental y potencial, bajo un rol transformador y reparador como jueces y juezas ante la desigualdad formal, material y estructural al momento de sustanciar los procesos judiciales hasta su decisión oral a través de resoluciones o sentencias ya que al momento de juzgar son agentes de cambio en el diseño y ejecución del proyecto de vida de las personas.

El fin del Derecho también es combatir las relaciones asimétricas de poder y los esquemas de desigualdad que afectan el desarrollo de las mujeres dentro de la sociedad. El mandato de la igualdad requiere eventualmente de quienes imparten justicia, un ejercicio de deconstrucción de conceptos patriarcales, machistas en la forma en que se ha interpretado y aplicado el derecho, despojándose de todo tipo de prejuicios y estereotipos que pueden estar arraigados por la forma de crianza en sus hogares (Sánchez, Sánchez Espinosa, Sánchez Espinosa \& Sánchez Espinosa, 2019).

Para ello, es necesario tomar en cuenta dentro de los procesos de evaluación indicadores que brinden un marco para cuantificar de forma sistemática la información relacionada con el número de casos y sustanciación de causas que se tramitan con 
frecuencia en la aplicación de variables con perspectiva de género en los procesos, cuyos casos devienen de violencia contra las mujeres (Cumbre Judicial Iberoamericana Comisión Permanente de Género y Acceso a la Justicia, 2015).

La utilización del lenguaje apropiado, la eficacia en el uso de los criterios valorados con enfoques de igualdad, seguimiento y ejecución en las resoluciones o sentencias son necesarios para la protección de los derechos humanos; por consiguiente, el objetivo de la presente investigación consiste en argumentar la aplicación de la perspectiva de género incorporando los diferentes enfoques de igualdad, su interrelación en las decisiones judiciales con respecto al derecho a la igualdad y la no discriminaciónn de las mujeres como medio preventivo, y de erradicacion de estereotipos de género y prejuicios sociales.

\section{DESARROLLO}

\section{Enfoques de igualdad desde una perspectiva de género}

Para comprender lo que son los enfoques de igualdad desde una perspectiva de género, se debe entender con precisión la diferencia de sexo y género. El sexo hace referencia si es hombre o mujer, en el sexo está inmerso las características biológicas al momento de nacer y en cuanto al género referente a los diversos roles, comportamientos, actividadades atribuidas a las personas en una sociedad conforme el tiempo en los cuales dichos roles son especificados para hombres y mujeres, es decir categorizando como masculino y femenino. Se debe considerar además que la identidad de género es referente a la propia experiencia de cada ser humano, que no necesariamente corresponde a su sexo, sino a como se identifica, siendo independiente estos factores el uno del otro; así como la orientación sexual de cada ser humano se basa no solo en el aspecto emocional, afectivo y sexual por otras personas sean del mismo o diferente sexo o género, categorizando a la persona por su orientación sexual como heterosexual, homosexual o bisexual (ONU Mujeres, 2016). 
En lo que respecta a las características y atributos que son reconocidos por la sociedad como masculinos o femeninos y el valor que se les asigna en una determinada sociedad, estas devienen no solo desde la socialización dentro de la familia, ya sean en escuelas, colegios, universidades, sino también tienen relevancia en el ámbito laboral, social y político. Se observa que todo lo inherente a las normas, roles y relaciones de género, especialmente a esta última; relaciones sociales que unen a hombres y mujeres, sigue denotándose una distribución de poder en el ámbito laboral y político, así como la dificultad en especial para las mujeres al acceso de cargos públicos; pues, se puede evidenciar en la sociedad que ciertas actividades, tareas y responsabilidades se asignan a los hombres y excluyen las aptitudes, habilidades de mujeres dejando entrever que los prejuicios y estereotipos afectan derechos como el acceso a la salud, al trabajo, a la educación, a la participación política (Consejo Nacional para la Igualdad de Género, 2017).

Estos enfoques de igualdad con perspectiva de género, se encuentran definidos en la Ley Orgánica Integral para Prevenir y Erradicar la Violencia contra las Mujeres, que entró en vigencia el 5 de febrero del año 2018, que deben ser considerados dentro de los argumentos por parte de los operadores de justicia y aplicados desde una perspectiva de género, que para cada caso concreto pueden enmarcar en enfoques de género, de interculturalidad, intergeneracinal, de movilidad humana, de discapacidades, de integralidad y su interrelación desde la perspectiva de género, basada en el principio de igualdad de los derechos humanos así como el derecho expresado en la igualdad y no discriminación ante la ley, todos transversalizados hacia el enfoque de derechos humanos; pues, estos últimos son derechos inalienables, irrestrictos que nadie bajo ningún concepto puede privar a persona alguna de estos derechos por su raza, nacionalidad, religión, enfermedad o discapacidad, orientación sexual, condición social, identidad de género, ideología polítca (ibídem).

Cuando transversalizamos hacia un enfoque de derechos humanos, éste se centra especialmente en los grupos poblacionales marginados, excluidos y discriminados, 
siempre se requiere un mayor análisis de la norma de género, de diferentes formas de discriminación y de los desequilibrios de poder a fin de garantizar que las intervenciones lleguen a equilibrar a los segmentos más vulnerados de la población. Por ejemplo, cuando el operador de justicia, conforme al caso concreto motive su resolución debe justificar los diversos enfoques si se trata de una mujer de comunidad, deberá considerar su entorno no solo social sino cultural, por ello se denomina un enfoque desde la interculturalidad porque determina características culturales propias y particulares que diferencian del resto de la sociedad, así como las culturas de los países occidentales y orientales (Clavero, 2010).

El enfoque intergeneracional desde la perspectiva de género es aquel que está dirigido a un determinado grupo de personas, el cual se delimita en el rango de edad, tomando en cuenta el producto y resultado de una construcción social histórica y cultural; por ejemplo la visión social, de roles y comportamientos de una persona de la tercera edad, es totalmente distinta a de los niños, niñas y adolescentes conforme a la época actual, pues los derechos específicos basan en la existencia de necesidades conforme al ciclo de vida desde una infancia, niñez, adolescencia a la adultez, y es el operador de justicia que desde este enfoque intergeneracional desde una perspectiva de género le corresponde en el caso concreto identificar, analizar y aplicar el mismo a fin de garantizar los derechos ponderando el principio de igualdad y no discriminación, en especial énfasis dirigido a las mujeres sean niñas, adolescentes, mujeres embarazadas, adultas mayores, mujeres que padezcan alguna enfermedad catastrófica 0 discapacidad de cualquier índole (Ley Orgánica Integral para Prevenir y Erradicar la Violencia Contra las Mujeres, 2018).

Enfoque desde la movilidad humana que deben conocer e incluir dentro de la justificación al argumentar los operadores de justicia se fundamenta el derecho universal a la libre movilidad humana dentro o fuera de un territorio, es decir la movilización de personas de un lugar a otro. Las personas por diversas razones cambian su destino sean por períodos cortos o largos, sea dentro o fuera del país, ya 
sea emigrando, en tránsito de un lugar a otro, retornando a su país de origen, inmigrando, en calidad de refugiados o desplazándose de manera forzosa abandonar sus hogares (ibídem).

Enfoque de discapacidades, este determina la salud, su condición física, emocional e intelectual a consecuencia de alguna alteración de la estructura o función que limita a una persona restringiendo su participación social, laboral, educativa, generando en estas personas que padecen de discapacidades barreras sociales dentro de la sociedad. Hay que tener en cuenta que un tipo de discapacidad podría generar desde su nacimiento, o en cualquier momento o ciclo de su vida.

Enfoque de género, constructo social, cultural de roles y comportamientos entre hombres y mujeres, tiene por finalidad modificar los mismos y que sus prácticas sociales garanticen la efectividad en la igualdad de oportunidades entre las personas, así como una vida libre de todo tipo de violencia en todo ámbito público y privado.

Enfoque de integralidad, hace referencia a que la violencia a las mujeres, en todas sus etapas de vida es estructural y multicausal, presente en todos los ámbitos de la vida en la que las mujeres se desarrollan (ibídem).

\section{Estereotipos y prejuicios contra la violencia a las mujeres}

Los estereotipos de género se basan sobre los atributos de género, las diferencias y roles tanto de hombres como de mujeres, las características estereotipadas hacia los hombres los describen como competitivos, inteligentes, independientes, fuertes, interesados en los bienes públicos; mientras que los que estereotipan hacia las mujeres las representan como cooperadoras, atentas, comunicativas, acogedoras, interesadas en los bienes privados (ONU Mujeres, 2016).

Los estereotipos de género pueden originar una discriminación en detrimento de todas las personas, fundadas en la percepción que se tiene del sexo/género y en la estigmatización de las características que se perciben como femeninas o como una violación a las normas tradicionales de género, ocasionando un trato injusto que recibe 
una persona o un grupo de personas por cualquier razón como, por ejemplo, la religión, color de la piel, orientación sexual, formas diversas de pensamiento, enfermedades 0 discapacidades, etc., los mismos que recaen en diversas formas de discriminación ya sean de forma directa y visible, por ejemplo: cuando las mujeres amas de casa no generan recursos propios, no pueden estudiar una carrera o salir solas; de forma indirecta por ejemplo cuando una mujer quiere incursionar en una carrera policial o militar sea por su estatura no podría cumplir el perfil exigido, ya que puede delimitarse el mínimo de estatura; otra forma múltiple se da ya será por la religión que profesa, por el color de la piel, por la edad, estado de salud, orientación sexual, por ejemplo un hombre de raza negra o una mujer lesbiana (ONU Mujeres, 2016).

Prejuicios sociales, prejuzgar a las personas por su forma de vestir, de pensar, sentir, por su color de piel, este consiste en emitir juicios antes de conocer a la persona. En la primera impresión o mirada se sitúa a la persona y se posiciona según nuestras creencias sobre nosotros mismos, cuando visualizamos su parte física (Villamar Pallás, 2018). En la tabla 1 se presenta los estereotipos masculinos y femeninos construidos en la sociedad.

\section{Tabla 1}

Estereotipos de Género (Masculinos versus Femeninos)

\section{Estereotipos Masculinos}

Estabilidad emocional

Dinamismo/agresividad

Tendencia al dominio

Objetividad/racionalidad

Poco aspecto/afectivo

Valentía/Independencia

Cualidades/intelectuales

Aptitudes para las ciencias

Riesgo/aventura

\section{Estereotipos Femeninos}

Inestabilidad emocional

Intuición/ falta de control

Aspecto/afectivo/marcado

Pasividad/irracionalidad

Frivolidad/ternura

Miedo/Dependencia

Cualidades/manuales

Aptitudes para las letras

Debilidad/sumisión 


\section{Estereotipos de género dentro de la jurisprudencia de la Corte Interamericana de Derechos Humanos}

Es importante tomar en cuenta que las Cortes Internacionales, órganos de protección de derechos humanos referente a sus decisiones son de trascendental relevancia por cuanto identifican los estereotipos enquistados no solo en normas legales sino también institucionalizadas públicamente, y al momento del conocimiento de causas judiciales influyen en el razonamiento de jueces y juezas. Debe comprenderse que estas decisiones judiciales aportan a sensibilizar, concientizar e identificar los efectos del uso de estereotipos en la vida cotidiana de las mujeres, así como el ejercicio pleno y efectivo de sus derechos. En los últimos años la Corte Interamericana de Derechos Humanos justifica la importancia de sus decisiones judiciales que se incorpore la perspectiva de género, con especial énfasis en los efectos que producen y reproducen los estereotipos.

Se señala que la Corte Interamericana de Derechos Humanos ha tardado en adoptar un enfoque de género sobre el ejercicio de los derechos humanos por parte de las mujeres, (Medina, 2003; Palacios Zuloaga, 2008; Tramontana, 2011). Ya en la década de 2000, la Corte Interamericana de Derechos Humanos ha superado deficiencias referente al enfoque de género tomando a consideración de cómo el uso de los estereotipos afecta la vida de las mujeres por ende el ejercicio pleno de sus derechos (Cardoso Onofre de Alencar, 2015), y cuando los estereotipos de género se adhieren a los prejuicios sociales, estos inmediatamente obstaculizan en especial a las mujeres dando como resultado la discriminación, expresada en prácticas discriminatorias, estereotipadas por el constructo de una sociedad que agravan y se manifiestan en razonamientos y lenguajes emitidos por autoridades (Caso Gónzález y otras vs. México, 2009). 


\section{Herramientas y guías desde la perspectiva de género en la aplicación de} resoluciones o sentencias dentro de la Administración de Justicia

El derecho de las mujeres a vivir libres de todo tipo de violencia, sea física, psicológica, sexual, patrimonial, política, que recae en discriminación, se encuentra bajo mecanismos de protección internacional, que protegen el derecho de las mujeres a vivir libres de violencia en todas las sociedades sin importar su raza, cultura, etnia, religión, estado civil, nivel social, identidad de género, orientación sexual, enfermedad o discapacidad (Aldana Zavala \& Valles González, 2018).

Por ejemplo la Convención de Belém do Pará es el uno de los instrumentos internacionales que ha tomado peso y fortalecido dentro sistema interamericano, así como la Convención sobre la eliminación de todas las formas de discriminación contra la mujer, quedando clara evidencia ante los estados parte que la violencia contra las mujeres no trata de esferas privadas sino es un problema público y prevalente, en el cual las acciones estatales deben fortalecer políticas públicas para cumplir efectivamente dichas acciones de prevención, investigación, sanción y reparación.

Un eje fundamental evitar la impunidad y de-construir los estereotipos de género y prejuicios sociales que atentan con el principio de igualdad y no discriminación vulnerando los derechos humanos de niñas, adolescentes, mujeres con discapacidad, adultas mayores, mujeres embarazadas, por ello es fundamental que en cada caso concreto los operadores de justicia analicen el perfil y comportamiento de la persona agresora porque otro eje fundamental es encontrar la verdad de los hechos. (Consejo de la Judicatura, 2018).

\section{Parámetros básicos que los operadores de Justicia pueden aplicar con perspectiva de género}

Si bien cada instancia y materia especializada tiene sus propias particularidades procesales y sustantivas, es posible hacer una abstracción del proceso mediante la cual se llega a una resolución o sentencia y revisar que en todas sus fases procesales por 
parte de los operadores de justicia incorporen los enfoques de igualdad desde una perspectiva de género, aplicando a cada caso concreto en el que deviene de conflictos que violenten los derechos de las mujeres. Para efectivizar es menester tomar en cuenta los siguientes parámetros básicos, tales como: combatir las relaciones asimétricas de poder, la desigualdad social que establecen la forma y ejecución del proyecto de vida de las personas sean hombres y mujeres. El rol transformador de jueces y juezas forma parte de un aporte jurisprudencial que destruyan los prejuicios y estereotipos y renuevan nuevas formas del comportamiento en las relaciones sociales que permiten garantizar los derechos de las personas, previniendo nuevos conflictos sociales aplicando el derecho como así lo aporta la guía para la aplicación del modelo de incorporación de la perspectiva de género en las sentencias (Cumbre Judicial Iberoamericana Comisión Permanente de Género y Acceso a la Justicia, 2015).

Es necesario aplicar la perspectiva de género en las actuaciones y decisiones jurisdiccionales con la finalidad de que los operadores de justicia actúen con imparcialidad, identifiquen situaciones de desventaja discriminatorias, de violencia basada en género y adopten los procedimientos que más favorezcan al respeto de la dignidad de las mujeres así como la protección de sus derechos. Esta obligación de los jueces y juezas es garantizar derechos de las mujeres en procesos judiciales que devienen de conflictos de violencia en contra de ellas, evitando la revictimización y la impunidad de estos actos de violencia y discriminación en contra de ellas, pues al incorporar los enfoques de igualdad desde una perspectiva de género permite al juzgador o juzgadora identificar estereotipos considerados negativos, como por ejemplo: las mujeres son histéricas o escandalosas o aparentemente positivos como que las mujeres son protectoras con sus hijos; no obstante, ambos estereotipos concluyen condicionando la vida de las mujeres.

Aplicar la guía en la administración de justicia con perspectiva de género permitirá que los operadores de justicia analicen cada caso concreto tomando en cuenta los roles, estereotipos de género, situaciones de riesgo conforme a las circunstancias de 
hechos que permitan ampliar la aplicación de normas y conseguir como resultado final los argumentos con enfoques de igualdad desde una perspectiva de género para administrar justicia y no sólo aplicando leyes (Consejo de la Judicatura, 2018).

Resultados del test sobre enfoque de género, se realizó un test de diagnóstico con el objetivo de reflexionar sobre el grado de sensibilización de género que poseen los operadores de justicia en Ecuador tanto en su vida personal como laboral, referente a los conocimientos sobre el enfoque de género, en el que constan 16 ítems, demostrando en sus respuestas estar de acuerdo o en total desacuerdo con las frases descritas que marcan estereotipos de género y prejuicios sociales, test que se desarrolló a un grupo objetivo in situ, focalizado a 32 operadores de justicia del cantón Machala, 12 hombres y 20 mujeres, quienes ejercen funciones en distintas unidades judiciales penal, civil, laboral, familia, violencia intrafamiliar. Entre las preguntas más destacadas, se obtiene como resultado:

Pregunta No. 1 ¿Un verdadero hombre sabe que comportarse como caballero (abrir la puerta del auto para que suba la mujer, pagar la cuenta), lo hace más hombre? 21 jueces y juezas están totalmente en desacuerdo y los 11 restantes de acuerdo.

Pregunta No. 4 ¿Cuando existen equipos de trabajo, las mujeres se desempeñan mejor en labores administrativas, en lugar de las de liderazgo? 25 jueces y juezas están ni en desacuerdo ni acuerdo y los 7 restantes de acuerdo.

Pregunta No. 11 ¿Solo una mujer jueza podrá entender verdaderamente las dificultades de romper con el ciclo de violencia? 18 jueces y juezas en desacuerdo y los 14 restantes totalmente de acuerdo.

Con los resultados descritos se denota que los prejuicios sociales y estereotipos de género siguen enraizados mentalmente en los operadores de justicia, y que se reproducen en su vida familiar y laboral (Escuela de la Función Judicial, 2018). 


\section{Análisis de Casos del Cantón Pasaje, Machala - Provincia de El Oro}

El objetivo que se analizó es sobre la conceptualización de estereotipos de género y prejuicios sociales en el lenguaje utilizado, por quienes se encontraban inmersos dentro de esta causa judicial, como informes periciales, teoría del caso, testimonios, alegatos en defensa del procesado.

Tribunal de Garantías Penales de El Oro, con sede en el Cantón Machala, Causa N ${ }^{\circ}$ 07711-2015-00276, con fecha jueves 07 de julio del 2016, las $18 \mathrm{~h} 16$ se dictó sentencia condenatoria, declarando culpable al procesado A.M.T.Ch., como autor del delito de lesiones, imponiendo un pena privativa de ochenta días, multa equivalente a dos salarios básicos unificados del trabajador en general, así como la reparación integral de la víctima. Interponen Recurso de Apelación parcial a dicha sentencia condenatoria por parte de Fiscalía General del Estado y acusación particular interponen Recurso de Apelación parcial a la sentencia condenatoria ante el inmediato superior, fundamentado de que el Tribunal no valoró medios probatorios presentados por fiscalía y acusación particular, cuando se acusó por el delito de femicidio por el grado de tentativa y fue juzgado por el delito de lesiones, por cuanto el procesado quiso quitarle la vida a L.S, quien en su testimonio narró hechos de violencia física, psicológica y sexual durante más de diez años de convivencia.

El médico valoró una incapacidad de siete días a la víctima por el golpe en la frente con un corte que determinó estético, dentro de la teoría del caso fiscalía argumentó que se trata de violencia de género, solicitando se revoque la sentencia por el delito de lesiones y sea sancionado por el delito de femicidio en el grado de tentativa. La defensa del procesado argumentó que su ex conviviente tuvo una aventura con otra persona y abandonó el hogar, quedando sus hijas con él y que pretende quitarlas. En el caso concreto se identifica en la defensa del agresor estereotipos de género manifestando dentro de los hechos su cliente, es decir el procesado tiene a su cargo a sus dos hijas por descuido de la madre. 
El testimonio que rindió la Teniente Política declara que cuando la víctima llegó a poner la denuncia, llegó bien vestida, peinada y que no vio que haya sido agredida. Dentro del presente caso es importante resaltar lo que manifiesta la psicóloga de la escuela donde estudian las hijas de la víctima y el procesado quien indicó que por parte del rector se ordenó que no permitan el ingreso a la madre, y en las entrevistas realizadas por parte de la psicóloga a las niñas referían temor al momento que llegaba su madre a visitarlas, poniéndose temerosas e indicando que no la quieren ver porque su madre toma mucho, es decir ingiere bebidas alcohólicas y está con hombres. Dentro del presente caso las expresiones dadas por las niñas referente a su madre, denotan estereotipos de género y prejuicios en las niñas de corta edad, muestran el rechazo, miedo a la madre por los constantes conflictos de violencia intrafamiliar entre los progenitores.

Unidad Judicial Familia, Mujer, Niñez, Adolescencia y Adolescentes Infractores Sede Cantón Machala - Causa №.07955-2014-1033 (Incidente Modificación de Tenencia) Sinopsis, dentro del presente caso trata de los mismos sujetos procesales de femicidio en grado de tentativa descrito en el caso dentro de la presente investigación, en que la tenencia de sus tres hijas fue otorgado al procesado, por los conflictos de violencia intrafamiliar y la sentencia condenatoria el progenitor fue privado de su libertad, y la progenitora víctima de violencia deduce un incidente solicitando la tenencia de sus hijas.

El Juez resolvió modificar la tenencia a favor de la progenitora, tomando en cuenta los informes presentados por el equipo técnico quienes concluían que el delito de femicidio en grado de tentativa en contra de la progenitora respecto al vínculo de la madre con sus hijas generó afectación en las niñas porque no querían ver a su madre ya que por parte de la abuela paterna quien se quedó bajo la responsabilidad de las nietas es quien expresa total rechazo a la progenitora de sus nietas, expresadas en faltas de respeto sin importar la presencia de las menores de edad, lo que naturalmente ha incidido en el comportamiento de ellas hacia su madre, concluyendo en el informe social 
que la progenitora se encuentra en buenas condiciones de volver a tener bajo su cuidado a sus hijas, se halla realizando un curso de auxiliar de enfermaría intensivo, y cuenta con un trabajo.

Dentro del presente caso se puede determinar que se continua a la mujer condicionando a vivir como la sociedad exige, los estereotipos y prejuicios sociales no se encuentran aún destruidos, una buena madre puede ser merecedora de sus hijas o hijos por tener un trabajo, por una carrera, por una forma de vestir, esa es la reflexión, sensibilización que está latente al identificar los estereotipos de género, analizar un caso que deviene de violencia contra la mujer, y la importancia fundamental en la aplicación de enfoques de igualdad desde una perspectiva de género, a través de las herramientas como la guía para administración de Justicia con perspectiva de género.

\section{METODOLOGÍA}

El conocimiento científico que se ha desarrollado en la última década bajo el enfoque de igualdad de género ha roto paradigmas y ha establecido nuevos retos que buscan ser precisados y profundizados a efectos de perfeccionar el proceso investigativo, en este sentido, para desarrollar la presente investigación fue necesario realizar una contextualización considerando los antecedentes y el estado actual de los enfoque de igualdad desde la perspectiva de género, por consiguiente se llevó a cabo un estudio cuali - cuantitativo, el cual permitió comprender la complejidad de la construcción social de género, de violencia contra las mujeres y el principio de igualdad y no discriminación.

Los métodos fueron sistémico - estructural, a través de los cuales se analizó si los operadores de justicia al momento de resolver sus sentencias, aplican los enfoques de igualdad, la guía para la administración de justicia con perspectiva de género. Esta investigación se basó además en técnicas de revisión documental, encuestas y grupos focales (Test diagnósticos); con la finalidad de asegurar una adecuada participación de hombres y mujeres, y conocer sus experiencias y situaciones se invitó a participar de 
forma libre y voluntaria a cincuenta (32) jueces y juezas de primer nivel, de diferentes unidades judiciales (Maldonado, Erazo, Pozo y Narváez, 2020)

\section{APORTES GENERADOS}

El proceso de construcción social inicia a partir del nacimiento de las personas y se mantiene durante toda la vida a través de los mandatos sociales, es a partir de la diferencia sexual entre hombres y mujeres que se da un proceso de construcción identaria que limita el desarrollo de mujeres y hombres, porque dependiendo de las costumbres, creencias, tradiciones, pensamientos, religión, se encasilla a las mujeres y hombres en parámetros de comportamientos pre establecidos.

La violencia de género por años y años ha sido naturalizada y vista como una verdad que por décadas y estas han sido evidentemente demostrado la vulneración de derechos especialmente con mayor énfasis hacia las mujeres, debido al constructo social, con estructuras mentales machistas dentro de la sociedad civil y cómo manifestaciones de estas expresiones de poder que se han identificado diversas formas de violencia, y que se han transformado de acuerdo a la época.

El rol de los operadores de justicia, tienen el deber de ser imparcial, respetar la ley, tomar en cuenta el principio de igualdad y no discriminación así como conocer la obligación de aplicar directamente las normas constitucionales y las previstas en los instrumentos internacionales de derechos humanos, considerando las recomendaciones que los organismos realizan al estado ecuatoriano, como la CEDAW y la Convención de Belem Do Pará.

Los operadores de justicia actualmente disponen de herramientas necesarias como la guía para administración de justicia con perspectiva de género, para la aplicación en las sentencias o resoluciones (ver figura 1), las mismas que jueces o juezas emiten son las que permiten realizar cambios sociales, deben erradicar los estereotipos de género y prejuicios sociales, incorporar los enfoques de igualdad, como el de género, de interculturalidad, intergeneracional, de movilidad humana, de discapacidades, desde 
una perspectiva de género y todos estos transverzalizando hacia el enfoque de derechos humanos.

En la actualidad se toma como referencia y jurisprudencia la Sentencia $N^{\circ}$. 525-14EP/20 dictada el 8 de Enero del 2020 por la Corte Constitucional de Justicia del Ecuador, referente a la obligatoriedad de operadores de justicia en desarticular la aplicación de estereotipos de género en la resolución de las causas, dentro del análisis constitucional valoran positivamente la fundamentación de la Corte Nacional referente a los estereotipos de género y prejuicios sociales que responden a modelos patriarcales que como resultado genera en la sociedad desigualdad y discriminación hacia las mujeres estos interrelacionados por su sexo, identidad de género, condición social, etnia, religión, cultura, raza, con lo que se concluye dentro del trabajo investigativo la relevancia de incorporar los enfoques de igualdad, como género, intercultural, intergeneracional, de movilidad humana, de discapacidad desde una perspectiva de género y su aplicación con las herramientas y guías para las resoluciones o sentencias a través de la administración de justicia (Corte Constitucional del Ecuador, 2020) 


\section{REFERENCIAS CONSULTADAS}

1. Aguado, T. (2012). El principio de proporcionalidad en la jurisprudencia del Tribunal Constitucional peruano. En J. Urquizo, \& N. Salazar, Derecho constitucional Penal. Lima: IDEMSA.

2. Aguilar, P. (septiembre - octubre de 2018). Los menores infractores en la ciudad de México. Revista Jurídica Electrónica Hechos y Derechos(47), s/n.

3. Arboleda, C., Baquero, M., y Domínguez, M. (enero - diciembre de 2010). La inimputabilidad del menor en el Sistema Penal Colombiano. Universitas Estudiantes(7), 157-174.

4. Arnold, R., Martínez, J., y Zúñiga, F. (2012). El principio de proporcionalidad en la jurisprudencia del Tribunal Constitucional. Estudios Constitucionales, 10(1), 65116.

5. Asamblea Nacional. (20 de octubre de 2008). Constitución de la República del Ecuador. Registro Oficial 449 . Quito, Pichincha, Ecuador: Editora Nacional.

6. Asamblea Nacional. (2012). Código Orgánico de la Niñez y Adolescencia. Quito, Pichincha, Ecuador: Corporación de Estudios y Publicaciones.

7. Asamblea Nacional. (10 de febrero de 2014). Código Orgánico Integral Penal. $R$. O. No. 180. Quito, Pichincha, Ecuador: Editora Nacional.

8. Ávila, R. (2011). El neoconstitucionalismo transformador: el Estado y el derecho en la Constitución de 2008. Universidad Politécnica Salesiana. Universidad Andina Simón Bolívar, Sede Ecuador. Fundación Rosa Lusemburg. Quito, Pichincha, Ecuador: Abya Yala. Recuperado el 18 de abril de 2018, de http://hdl.handle.net/10644/2984 
9. Barnes, J. (septiembre-diciembre de 1998). El principio de proporcionalidad. Estudio preliminar. Cuadernos de Derecho Público(5), s/p.

10. Bernal, C. (2007). El principio de proporcionalidad y los derechos fundamentales. Bogotá: Centro de Estudios Políticos y Constitucionales.

11. Cabanellas, G. (2010). Diccionario Jurídico de Derecho Usual . Buenos Aires: Heliasta.

12. Calero, A. (12 de septiembre de 2012). Adolescentes infractores, en la mira de Código Penal. Diario El Telégrafo, pág. s/n. Recuperado el 26 de enero de 2020, de http://www.telegrafo.com.ec/noticias/judicial/item/adolescentes-infractores-enla-mira-de-codigo-penal.html

13. Carbonell, M. O. (2002). Estado de Derecho. México: Siglo XXI Editores.

14. Carreño, B. (2017). Las penas privativas de otros derechos y sus problemáticas operativas: un análisis a partir de la jurisprudencia colombiana. Trabajo de Grado. Bogotá, Colombia: Universidad Santo Tomás.

15. Cea, J. L. (2002). Derecho Constitucional chileno. Santiago de Chile: Editorial de la Universidad Católica de Chile.

16. Couture, E. (1978). Vocabulario Jurídico. Buenos Aires, Argentina: Depalma.

17. Díaz, A. (2015). Reglas de Beijing, su aplicación en el marco de las leyes 19.970 y 20.084. Revista de Estudios de la Justicia, 19, 207-214. doi:doi:10.5354/07184735.2015.36193

18. Donna, E. (2011). Derecho Penal, Parte General. Buenos Aires: Editorial Rubinzal Culzoni. 
19. Duque, L. Z. (2016). La responsabilidad penal de los menores infractores y la edad para la imputabilidad de los adolescentes en delitos contra la vida. Tesis de pregrado. Quito, Pichincha, Ecuador: Universidad de las Américas. Recuperado el 26 de enero de 2020, de http://dspace.udla.edu.ec/handle/33000/5102

20. Fariña, F. A. (2011). Grado de competencia social y comportamientos antisociales, delictivos y no delictivos en adolescentes. Revista Latinoamericana de Psicología, 43(3), 473-486. Recuperado el 26 de enero de 2020, de www.scielo.org.cospdf

21. Fernández, J. (1999). Principios y normas rectoras del derecho penal. Bogotá: Leyer.

22. Ferrajoli, L. (1986). Derecho y razón. Teoría del Garantísmo penal. Madrir: Trotta.

23. García, O. (2019). La contribución de la jurisprudencia al endurecimiento de la respuesta a los menores infractores. Revista Electrónica de Ciencia Penal y Criminología(21), 1-44.

24. Gómez, J. O. (2001). Derecho penal. Parte General (Vol. I). Bogotá: Doctrina y ley.

25. Ibáñez, V., y Graña, J. (2018). Madurez psicosocial y comportamiento delictivo en menores infractores. Psicopatología clínica Legal y Forense, 18(1), 1-12. Recuperado el 25 de enero de 2020, de www.dialnet.com

26. Jefatura del Estado. (13 de enero de 2000). Ley Orgánica 5/2000 Reguladora de la Responsabilidad Penal de los Menores . BOE-A-2000-641, No. 11. Madrid, España: Boletín Español.

27. Lopera, G. (2006). Principio de proporcionalidad y Ley penal. Madrid: Centro de Estudios políticos Constitucionales. 
28. Maldonado García, V. L., Erazo Álvarez, J. C., Pozo Cabrera, E. E., \& Narváez Zurita, C. I. (2020). Violencia económica y patrimonial. Acceso a una vida libre de violencia a las mujeres. Iustitia Socialis, 520.

doi:http://dx.doi.org/10.35381/racji.v5i8.588

29. Mezger, E. (2005). La Culpabilidad. Bogotá: Leyer.

30. ONU. (29 de noviembre de 1985). Reglas Mínimas de las Naciones Unidas para la Administración de la Justicia de Menores o "Reglas de Beijing". Resolución 40/33.

31. Pabón, P. (2007). Comentarios al nuevo sistema de responsabilidad penal paramadolescentes. Bogotá: Ediciones Doctrina y Ley Ltda.

32. Pérez, M. (2013). Asesinos Adolescentes. Caretas(10), 1-10.

33. Ruíz, C. E. (2006). Teoría de los fines de la pena (Segunda ed.). Bogotá: U. Externado de Colombia.

34. Thornberry, T. G. (2013). Transición desde la delincuencia juvenil a la delincuencia adulta. Revista Española de Investigación Criminológica, 11(2), s/n.

35. Vargas, L. (2010). Las penas y medidas de seguridad consecuencia del Derecho Punitivo en México. Letras Jurídicas(10), 1-10.

36. Villaverde, I. (2008). La resolución de conflictos entre derechos fundamentales. El principio de proporcionalidad. En M. Carbonell, El principio de proporcionalidad y la interpretación constitucional. Quito: Ministerio de Justicia y Derechos Humanos.

37. Yanac, J. (2017). El delito de estafa y el principio de proporcionalidad de la pena en el Código Penal peruano vigente. Grado Académico. Lima, Perú: Universidad 
Iustitia Socialis. Revista Arbitrada de Ciencias Jurídicas.

Año V. Vol. V. N¹. Edición Especial. 2020

Hecho el depósito de Ley: FA2016000064

ISSN: $2542-3371$

FUNDACIÓN KOINONIA (F.K). Santa Ana de Coro, Venezuela

Rossi Fabiola Peñafiel-Bermeo; Cecilia Ivonne Narváez-Zurita; José Luis Vázquez-Calle; Juan Carlos Erazo-Álvarez

Inca Garcilaso de la Vega. Recuperado el 26 de enero de 2020, de http://repositorio.uigv.edu.pe/handle/20.500.11818/2119.

(C2020 por los autores. Este artículo es de acceso abierto y distribuido según los términos y condiciones de la licencia Creative Commons Atribución-NoComercial-Compartirlgual 4.0 Internacional (CC BY-NC-SA 4.0) (https://creativecommons.org/licenses/by-nc-sa/4.0/). 